\title{
EFICIÊNCIA NA ARRECADAÇÃO TRIBUTÁRIA DOS MUNICÍPIOS POTIGUARES
}

\author{
Manoel Dantas das Chagas Neto ${ }^{1}$ \\ Francisco Danilo da Silva Ferreira ${ }^{2}$ \\ José Antonio Nunes de Souza ${ }^{3}$
}

RESUMO: O objetivo deste trabalho foi verificar o desempenho tributário dos municípios do Estado do Rio Grande do Norte no período de 2002 a 2016. Metodologicamente, estimou-se a Fronteira Estocástica de Produção de Impostos, desenvolvida por Battese (1992). Realizou-se uma análise descritiva, comparando a taxa de crescimento das receitas próprias com as taxas de crescimento do FPM e PIB setorial. Após a estimação do modelo econométrico, observou-se que a variável população e o PIB de serviços impactaram de forma positiva sobre as receitas. Por outro lado, o FPM gerou ineficiência na arrecadação própria, causando um efeito "Preguiça Fiscal" nas receitas.

Palavras-Chave: Eficiência; Municípios; Fronteira Estocástica; Preguiça Fiscal.

\section{EFFICIENCY IN TAX COLLECTION OF POTIGUARES MUNICIPALITIES}

ABSTRACT: The objective of this study was to verify the tax performance of the municipalities of the State of Rio Grande do Norte for the period from 2002 to 2016. Methodologically, it was estimated the Stochastic Frontier of Taxes Production, developed by Battese (1992). In a descriptive analysis, compare the growth rate of the own revenues with the rates of the FPM and the sectorial PIB. After the frontier estimation, was observed that the population and the PIB of services had a positive impact on revenues. Still, FPM creates inefficiency in own revenues, causing a "Fiscal Sloth" effect on revenues.

Keywords: Efficiency; Counties; Stochastic Frontier; Fiscal laziness.

\footnotetext{
${ }_{1}^{1}$ Graduado em Economia (UERN). E-mail: manoeldantas100@hotmail.com

${ }^{2}$ Graduado em Economia (UERN). Mestrado em Economia (UFRN). Professor Assistente da (UERN). Doutorando em Economia (UFPB). E-mail: ffdaniloferreira@gmail.com.

${ }^{3}$ Mestrado em economia (UFRN). É especialista em Economia da Saúde (USP). Graduado em Economia (UERN). Professor do departamento de economia (UERN). E-mail: raylakeyla@hotmail.com.
} 


\section{INTRODUÇÃO}

O federalismo fortificou-se no Brasil na década de 1980, junto a Constituição Federal de 1988 e consiste numa maior divisão de poderes, direitos e responsabilidades dos Estados e Municípios perante a União. Isto se deve ao fato de os Estados e municípios apresentarem maior aproximação da população e suas reais necessidades e preferências, e com isto melhor adaptar as decisões, políticas públicas, ou serviços fornecidos pelo Poder Público (GIAMBIAGI; ALÉM, 2000).

Diante disto, os municípios adquiriram a responsabilidade de ofertar uma significativa quantidade de serviços públicos. Assim, estes necessitam de uma eficiente arrecadação na qual supra as necessidades e arque com os gastos para os investimentos necessários para o pleno funcionamento das políticas públicas de competência municipal. Porém, a maioria dos municípios, principalmente os menores e das regiões menos desenvolvidas do país, são dependentes financeiramente das transferências intergovernamentais, em sua maior parte do Fundo de Participação dos Municípios (FPM) (GOMES; MAC DOWELL, 2000).

A maior dependência destes municípios pelas transferências, faz com que em quaisquer quedas nestes repasses, como em períodos de crise financeira, atinja fortemente as contas públicas municipais, obrigando com isto aos municípios a traçarem um planejamento voltado a melhorar a arrecadação tributária municipal, evitando sonegações fiscais, renegociando dívidas, e com isto melhor eficiência na arrecadação.

Face a estes pressupostos, emergem os seguintes questionamentos: Do ponto de vista tributário, as prefeituras do Estado do Rio Grande do Norte são eficientes em sua arrecadação tributária municipal? Quais variáveis econômicas têm maior poder influenciador sobre seus resultados?

Diante do que foi apresentado acima, o objetivo do presente estudo é analisar a eficiência tributária dos municípios do Rio Grande do Norte durante os anos de 2002 a 2016. Metodologicamente, nesta pesquisa será utilizada a fronteira estocástica de produção de impostos, tendo como variável dependente a arrecadação tributária própria dos municípios potiguares (IPTU, ISS e ITBI), e as variáveis independentes o PIB setorial (agricultura, indústria e serviços), população, FPM, e através disto encontrar o potencial tributário da administração pública municipal. Para chegar a isto, utilizaremos dados da Secretaria do Tesouro Nacional 
(STN), por meio do FINBRA, para obter informações sobre a arrecadação e o FPM dos municípios, e para as demais variáveis, dados do Instituto Brasileiro de Geografia e Estatística (IBGE).

O presente estudo, justifica-se pelo fato de os municípios apresentarem recentemente dificuldades financeiras, afetando de forma significativa a oferta de serviços públicos, forçando os municípios a busca de solução, como também, preencher uma lacuna devido à escassez de estudos acerca dos níveis de desempenho fiscal dos municípios localizados no Estado do Rio Grande do Norte, além de contribuir para que as prefeituras consigam aperfeiçoar suas formas de arrecadar impostos, possibilitando com que consigam extrair boa parte de suas capacidades tributárias, evitando dependência financeira de outros entes federados.

Além desta seção, o trabalho é dividido mais quatro: a segunda seção consiste em uma revisão da literatura onde será discutida a conceituação teórica acerca da eficiência tributária, federalismo e estrutura das receitas municipais, além da revisão de alguns resultados empíricos de trabalhos de mesma natureza que este aplicados a outros entes da federação. Na terceira seção, será abordado os aspectos metodológicos que serão aplicados a este trabalho para se atingir os objetivos propostos. Em seguida é apresentado os resultados alcançados. E por último as considerações finais.

\section{FEDERALISMO E EVIDENCIAS DA TRIBUTAÇÃO MUNICIPAL}

\subsection{FEDERALISMO E DESCENTRALIZAÇÃO FISCAL NO BRASIL}

O Sistema Federativo consiste num conjunto de unidades federadas autônomas que unidas formam uma federação. Diferentemente de um Estado centralizado que concentra o poder na unidade central e do conglomerado onde se há forte autonomia dos entes subnacionais e menor poder da união, o Federalismo consiste numa maior divisão dos poderes políticos e constitucionais entre suas unidades subnacionais, porém com forte soberania do poder central sobre as demais unidades subnacionais. No Brasil conforme a Constituição Federal de 1988 em seu artigo $\mathrm{n}^{\circ}$ 18, divide-se em três esferas de governo: A União, os Estados/Distrito Federal e os Municípios (BRASIL, 1988. MENDES, 2004). 
O Federalismo Fiscal, por sua vez, consiste na divisão de atribuições e responsabilidades entre as unidades subnacionais de um país de forma descentralizada, determinando quem tem melhor competência para recolher determinados impostos, assim como quem melhor poderá oferecer os serviços públicos à população, de forma a potencializar a eficiência do setor público (MENDES, 2004).

Giambiagi e Além (2000) aponta que o processo de descentralização fiscal é justificado por três fatores, são eles: os fatores culturais, políticos e institucionais, os fatores geográficos e os fatores econômicos. Por fatores econômicos pode-se exemplificar a determinação de quais esferas de governo são mais eficientes na administração da arrecadação, dos investimentos públicos, além do fornecimento dos bens e serviços públicos. Uma justificativa cabível é a maior aproximação dos usuários dos serviços públicos com as esferas subnacionais, onde estas últimas podem vivenciar de perto as reais necessidades da população e traçar quais políticas públicas são necessárias para aplicar naquele local.

No Brasil a partir da década de 1980 e após a Constituição Federal de 1988, houve-se um forte processo de descentralização fiscal no qual resultou em uma maior divisão dos tributos que antes ficavam em sua maior parte nas mãos do governo central, com os Estados e municípios, sendo estes últimos os mais beneficiados neste processo que resultou numa maior autonomia das esferas subnacionais, onde os mesmos tiveram possibilidade tanto de fornecer os bens e serviços públicos, como também maior competência para arrecadar impostos.

Rezende (1992, apud AFFONSO, 1996, p.6) argumentam que:

\footnotetext{
"a possibilidade de acesso a uma receita não gerada no local, ou seja, a dissociação dos atos de gastar e de tributar estimula a tendência à emancipação irresponsável, fazendo com que se criem municípios sem base econômica própria, integralmente dependentes das transferências federais e/ou estaduais".
}

A Descentralização Fiscal deu-se após aumento constantes nos percentuais dos Fundos de Participação dos Estados e Municípios (FPE e FPM), na primeira metade da década de 1980, com as emendas constitucionais $n^{\circ} 23 / 1983$, que previa aumento nos repasses dos fundos, e posteriormente fortificou-se com a Constituição Federal de 1988. Segundo Affonso (1996), o Governo Central era oposto a Descentralização, enquanto os entes subnacionais o pressionavam devido à crise 
econômica instalada no final da década de 1970, o que resultou na inexistência de um plano nacional para a descentralização, deixando com isto o processo inconcluso.

\subsection{DESCENTRALIZAÇÃO NA ARRECADAÇÃO E RECEITAS MUNICIPAIS}

Para se entender o esquema de divisões sob a arrecadação de impostos no Brasil, Giambiagi e Além (2000) descrevem a lógica por cada ente federativo. Segundo eles, cabe à União recolher impostos que requerem um maior nível de centralização, já que os estados e municípios não poderiam ter domínio sob algumas variáveis, dificultando a cobrança, são eles: impostos sobre a renda, impostos sobre o comércio exterior, impostos regulatórios e alguns impostos específicos. Enquanto os Estados recolhem impostos sobre o consumo e a circulação de bens dentro da unidade federativa. Já os governos locais têm competência para tributar sobre patrimônios e impostos sobre a renda de serviços realizados no âmbito municipal (GIAMBIAGI e ALÉM, 2000).

A União recolhe impostos que requerem um maior grau de atenção quanto à evitar sonegações fiscais devido a maior facilidade de exportação do imposto ou mobilidade da base tributária de um município para o outro, ou de um Estado para outro Estado, considerando que um determinado cidadão muda de cidade ou Estado diante de uma maior ou menor alíquota de imposto cobrado pelas prefeituras, ou preferir cadastrar um veículo num Estado que ofereça menores alíquotas do Imposto sobre a Propriedade de Veículos Automotores (IPVA).

Entre os impostos recolhidos pela União estão o Imposto de Renda (IR) que é cobrado com base nos rendimentos de pessoas físicas ou jurídicas que atuem por todo o território do país; o Imposto sobre Produtos Industrializados (IPI), que é cobrado indiretamente no consumo da população; o Imposto sobre a Propriedade Territorial Rural (ITR), que no passado já pertenceu aos municípios e hoje é arrecadado pela União devido a ineficiência dos municípios na arrecadação dos mesmos; os Impostos sobre importações e exportações, que tem funções regulatórias, cabendo apenas ao Governo Federal arrecadar tais tributos, além do Imposto sobre Operações de Crédito, Câmbio e Seguros (IOF), gerado a partir de operações financeiras, como também de impostos únicos, cabendo só ao governo 
central arrecadar e posteriormente dividir com as demais esferas subnacionais em alguns casos.

Já os Estados/Distrito Federal têm domínio sobre o Imposto Sobre a Circulação de Mercadorias e Serviços (ICMS), arrecadados a partir do consumo de mercadorias, bebidas, bares, restaurantes, etc. sendo um dos principais impostos arrecadados por um país; o Imposto sobre a Propriedade de Veículos Automotores (IPVA), cobrado com base no registro de veículos no Departamento Estadual de Trânsito (DETRAN) no Estado de origem, tendo cada um uma alíquota própria; além do Imposto sobre Transmissão Causa-Mortis e Doação (ITCMD), cobrado a partir da transmissão de heranças, ou doações de bens dentro do território estadual.

Com a Constituição Federal de 1988, foi assegurado aos municípios maior autonomia nos gastos, como também na arrecadação tributária, facilitando e dando maior competência aos municípios na criação de novos impostos, taxas e contribuições de melhoria, de forma a facilitar com que os mesmos gerassem uma receita significativa para financiar serviços por eles próprios oferecidos.

Atualmente as receitas tributárias dos municípios são oriundas de várias fontes, seja pela a arrecadação própria municipal ou de transferências intergovernamentais vindas de outros entes federativos.

As receitas originárias da arrecadação própria dos municípios são constitucionalmente determinadas o: Imposto Predial Territorial Urbano (IPTU) que é determinado através do patrimônio imóvel dos munícipes com base na localização, estrutura, conservação do imóvel, etc.; o Imposto sobre Transmissão de Bens Imóveis (ITBI), oriundo da compra e venda de imóveis situados nos municípios; o Imposto Sobre Serviços (ISS) é retido através da prestação de serviços no interior do município, principalmente em municípios médios e grandes, onde se há grandes possibilidades de o imposto ser arrecadado; além de outras taxas e contribuições para melhorias, etc.

Porém, Moraes (2006) aponta que após a análise da evolução das receitas próprias dos municípios, o IPTU vem cada vez mais mantendo-se constante, enquanto o ISS apresenta-se com certa elasticidade, promovendo com isto melhores ganhos para os municípios no financiamento dos gastos públicos por parte das prefeituras.

Isto se dá devido ao Imposto Sobre Serviços ser extraído sobre a atividade econômica atuante no município, tendo em vista que em períodos de economia 
aquecida, este tende a apresentar níveis proporcionais sobre as receitas. Enquanto - IPTU dos municípios brasileiros, mantêm-se abaixo das médias dos países desenvolvidos e em países em desenvolvimento, mesmo com a implantação da Emenda Constitucional nำ29/2000, onde instituía a liberdade aos municípios em aplicar alíquotas progressivas sobre o imposto (MORAES, 2006; CARVALHO JR, 2006).

Outros tipos de recursos compõem as receitas municipais do país, entre eles estão as transferências intergovernamentais, que podem ter o caráter "devolutório", onde retornam ao município apenas os impostos que foram recolhidos sob os produtos, serviços e renda dos moradores, assim como as transferências que são compostas de impostos arrecadados pelas regiões/cidades mais ricas e posteriormente repassadas aos municípios.

O Fundo de Participação dos Municípios (FPM), é uma transferência intergovernamental repassada do Governo Federal para os municípios brasileiros. É composto por parcela de $22,5 \%$ da arrecadação pela União, e partes significativas do Imposto de Renda (IR) e do Imposto sobre Produtos Industrializados (IPI), distribuído com base na quantidade populacional de cada município, sendo que 10\% do valor total destinado às capitais estaduais, $86,5 \%$ repassados para os municípios do país, assim como 3,6\% representam uma parcela para suplemento aos municípios com maior número populacional (MENDES; MIRANDA; COSIO, 2008).

Além do FPM, os municípios contam com os repasses da quota-parte do Imposto sobre Circulação de Mercadorias e Serviços (ICMS) sob responsabilidade do Governo Estadual de cada unidade federativa. Este imposto é cobrado de maneira indireta, através de operações relativas a compra e venda de mercadorias e serviços de transporte intermunicipal e interestadual, além dos serviços de comunicação. Conforme a Constituição Federal de 1988, os municípios detêm direito à $25 \%$ do produto da arrecadação, aumentando significativamente a receita destes. Ao contrário do FPM, a quota-parte do ICMS redistribui maior parte de sua arrecadação para os municípios conforme as operações e serviços sejam realizados.

Estas parcelas das transferências tanto do governo federal quanto do governo estadual acabaram por desestimular que as prefeituras consigam por elas próprias serem autossuficientes do ponto de vista fiscal, ou seja, naturalmente os municípios 
foram perdendo suas capacidades de financiar por eles próprios seus gastos e investimentos.

Para os autores Boueri, Carvalho e Silva (2009), se há uma tendência a geração de ineficiências nos sistemas federativos, onde os governos federais ao diminuírem suas responsabilidades e aumentar as atribuições dos entes subnacionais, acabam por incentivar estes últimos a criarem dívidas desnecessárias ou entrarem em situações em que é preciso a intervenção da União em prestar-Ihes auxílios.

Segundo a hipótese de Ribeiro (1999), as transferências do Fundo de Participação dos Municípios (FPM) podem influenciar as prefeituras a não explorar eficientemente a base tributária dos municípios, podendo causar efeito tanto sobre o aumento do gasto público, quanto pela redução na arrecadação local.

Para Massardi e Abrantes (2016), essa preguiça fiscal dos municípios ocorre devido a fatores políticos, em que dada a existência de receitas não condicionantes em caixa, os gestores acabam por não estimular a fazenda municipal a instituir, arrecadar e fiscalizar os impostos recolhidos por meio das prefeituras municipais. Os autores apontam que com a existência destes recursos, os gestores acreditam que podem financiar os bens e serviços públicos sem ocasionar "insatisfação" no eleitorado local, não explorando com isto a capacidade de arrecadação própria destes municípios, que por vezes possuem atividade econômica que possa suprir através da tributação as demandas financeiras locais para a oferta de bens e serviços públicos aos munícipes.

Gomes e Mac Dowell (2000), põem em questionamento a tese de que estes repasses associados ao forte processo de descentralização instalado no Brasil acabaram por estimular o número de municípios no país no recente período pósConstituição Federal de 1988. Segundo os autores, o processo favoreceu que fosse tirado por parte do governo uma grande fatia de impostos arrecadados pelos grandes municípios para os pequenos, que não necessariamente são os que mais necessitam destes repasses, aumentando no período de 13 anos (1984-1997) o número de municípios brasileiros aumentaram em 34,3\%, destes novos municípios $78 \%$ tinham menos de dez mil habitantes. 


\subsection{EVIDÊNCIAS EMPÍRICAS DO IMPACTO DAS TRANSFERÊNCIAS SOBRE A ARRECADAÇÃO TRIBUTÁRIA}

Nesta seção trataremos da abordagem empírica acerca da eficiência na arrecadação tributária dos municípios e sobre os impactos que as transferências intergovernamentais nela ocasionam, apresentando as experiências já vivenciadas por outros entes afim de comprovar os fatos e dar maior solidez a pesquisa.

Siqueira, Lima e Paes (2016), aplicando a fronteira estocástica para a arrecadação tributária nos municípios pernambucanos, verificaram que com o passar dos anos a arrecadação das prefeituras foram reduzindo, principalmente nos municípios distantes da região metropolitana, segundo os autores devido as transferências intergovernamentais, em especial do Fundo de Participação dos Municípios (FPM). Segundo eles, no caso de Pernambuco, a região metropolitana é onde concentra-se maior renda per capita e detém melhores níveis de eficiência tributária. Para eles, a concentração de arrecadação provoca grandes desequilíbrios, e a solução para o problema estaria em aumentar a eficiência na arrecadação de municípios de outras regiões do Estado, nas quais apresentam níveis de eficiência inferiores.

Os autores chamam de "preguiça fiscal" o efeito causado pelo incremento da receita posta aos municípios e a redução no incentivo a arrecadação por parte das prefeituras, que acabam por não estimular a geração de receitas em razão da existência dos repasses, resultando em menores níveis de eficiência. Por outro lado, se há uma tendência aos municípios mais eficientes em estimular seus vizinhos, criando com isto grupos de eficiência, e vice-versa, os municípios ineficientes tendem a desestimular seus vizinhos e criarem grupos de baixa eficiência (SIQUEIRA, LIMA E PAES, 2016).

Ribeiro (1999, p.15), utilizando a fronteira estocástica aplicando aos municípios gaúchos identificou, dentre outras coisas, que os municípios apresentavam baixos níveis de arrecadação per capita e forte dependência das transferências vindas de outros entes subnacionais. Em seguida examinou se o Fundo de Participação dos Municípios (FPM) atende de fato ao seu papel constitucional de equilibrar as receitas dos municípios. Observaram com isto "uma possível correlação negativa entre recursos do FPM e esforço fiscal próprio dos 
municípios", o que se pode presumir que de fato o FPM atende seu papel constitucional.

Os autores Queiroz e Postali (2010, p.14) aplicando a fronteira estocástica aos municípios brasileiros, levando em consideração os royalties do petróleo em cidades contempladas com este tipo de recurso, identificaram uma certa diminuição do esforço fiscal das prefeituras. Em relação as transferências do FPM, os autores argumentam que "quanto maior a relação entre estes recursos e as receitas correntes, mais distante da fronteira eficiente se encontra o município".

Quanto as ineficiências na arrecadação impostos de competência dos municípios, os autores apontam que em relação aos royalties o IPTU é o imposto com maior ineficiência. Isso se deve ao fato da necessidade de um maior esforço por parte dos gestores municipais em fiscalizar, monitorar e definir alíquotas para a arrecadação. Estes por sua vez, não se sentem incentivados a realizar tal atividade, dada a existência das transferências (QUEIROZ; POSTALI, 2010).

Para eles, se há uma proporcionalidade entre o PIB per capita e a população municipal em relação a receita própria per capita, assim tanto maior o PIB per capita e o número populacional, maior a receita própria dos municípios (QUEIROZ; POSTALI, 2010).

\section{METODOLOGIA}

A presente seção busca apresentar os mecanismos metodológicos que possibilitaram o desenvolvimento da pesquisa proposta, em consonância com o objetivo geral e objetivos específicos a fim de obter os resultados pretendidos.

\subsection{NATUREZA DOS DADOS}

O objetivo deste estudo é analisar a eficiência tributária dos municípios potiguares no período de 2002 a 2016, assim como a evolução das receitas próprias municipais e os determinantes da arrecadação.

Os dados para a pesquisa consistiram em um conjunto de dados secundários, colhidos através de banco de dados de fontes distintas, sendo elas a Finanças do Brasil (FINBRA), plataforma criada pela Secretaria do Tesouro Nacional (STN) em colaboração com a Caixa Econômica Federal (CEF), no qual fornece um apunhado 
de elementos quantitativos acerca das informações contábeis das unidades subnacionais do Brasil. Além do banco de dados do Instituto Brasileiro de Geografia e Estatística (IBGE), que disponibiliza informações dos municípios brasileiros.

A amostra utilizada na pesquisa compôs 107 municípios dos 167 existentes no estado do Rio Grande do Norte, tendo em vista que apenas estes informaram todos os dados referentes a arrecadação tributária e transferências do Fundo de Participação dos Municípios (FPM) a Secretaria do Tesouro Nacional (STN), para que com isto possibilitar a pesquisa para o período de 2002 a 2016.

Os dados foram deflacionados de acordo com o Índice de Preços do Consumidor Amplo (IPCA), aplicado a cada ano do recorte temporal da pesquisa.

\subsection{FRONTEIRA ESTOCÁSTICA DE PRODUÇÃO DE IMPOSTOS}

Os estudos que englobam a mensuração da eficiência técnica se destacam através de trabalhos como os de Aigner, Lovell e Schmidt (1976) e os de Battese (1992). Ambos utilizam da correlação entre os insumos (inputs) e os produtos (outputs). Para eles, a produtividade varia de acordo com as diferenças de produção tecnológica aplicadas as firmas. Este modelo trata-se de um modelo de eficiência produtiva. O grau de eficiência é dado de acordo com a maximização de resultados, dada certa quantidade de insumos empregados a produção.

Os autores Aigner, Lovell e Schmidt (1976), um dos percursores na criação de um modelo econométrico para funções estocásticas incluindo um erro composto, pelo fato de os mesmos reconhecerem que eventuais distorções em relação a fronteira estocástica poderiam ser originárias devido a ineficiência dos produtores, ou choques adversos longe da possibilidade de resolução por parte do produtor. Conforme representação matemática a seguir:

$$
y_{i}=T E_{i} \cdot f\left(\boldsymbol{X}_{i}, \boldsymbol{\beta}\right) e^{v_{i}}
$$

Onde:

- $\quad y_{i}$ Se refere ao produto observado da i-ésima firma;

- $\quad \boldsymbol{X}_{\boldsymbol{i}}$ É um vetor de insumos utilizados no processo de produção pela i-ésima firma;

- $\quad \boldsymbol{\beta}$ É um vetor de parâmetros desconhecidos; e

- $\quad v_{i}$ Consiste numa variável aleatória irrestrita. 
Partindo disto, podemos entender que a fronteira estocástica é definida por dois componentes: a fronteira determinística representada por $f\left(\boldsymbol{X}_{\boldsymbol{i}}, \boldsymbol{\beta}\right)$, comum a todas unidades produtivas, e o segundo componente parte do princípio em deter o efeito dos choques aleatórios que interferem na eficiência do i-ésimo produtor.

A medida de eficiência técnica do i-ésimo pode ser definida entre a produção analisada e a capacidade máxima de produção, obtendo valores variáveis entre 0 e 1. Assim, quanto mais eficiente for a produção compreende-se como valores próximos ou iguais a um, e vice-versa, conforme fórmula a seguir:

$$
T E_{i}=\frac{y_{i}}{f\left(X_{i}, \beta\right) e^{v_{i}}}
$$

Outras considerações que podem ser atribuídas seria que para a viabilidade da medida de eficiência por meio da fronteira estocástica, considera-se o componente aleatório $v_{i}$ possua distribuição normal independente, possuindo média $\sigma_{v}^{2}$ (i.i.d), além de possuir distribuição independente de $u_{i}$. Sendo esta última uma variável aleatória não possuindo relação com as ineficiências na produção. Outra consideração que pode ser feita é que na fronteira estocástica de produção o erro possui valores abaixo de zero $\left(u_{i}>0\right)$.

Empiricamente, o modelo que será empregado no presente trabalho terá a seguinte forma:

$$
\begin{aligned}
& \text { receitapropria })=\beta \_0+\beta \_1 \ln (\text { pib agrigola })+\beta \_2 \ln (\text { pib industrial }) \\
& +\beta_{-} 3 \ln (\text { pib serviço })+\beta_{-} 4 \ln (\text { população })+\beta \_5 \ln (\text { cota do } f p m) \\
& \quad+\varepsilon_{-} i
\end{aligned}
$$

Onde a variável dependente receitapropria representa a arrecadação própria do município, e as variáveis independentes representam o PIB setorial da cidade, levando em consideração a produção agrícola, produção industrial, e de serviços; além da população, partindo do pressuposto que em cidades com população numerosa, se há uma tendência a lograr de uma maior arrecadação; e por último as transferências do Fundo de Participação dos Municípios (FPM), tendo em vista que a literatura das finanças públicas aponta que as mesmas causam um "efeito preguiça" sobre a arrecadação municipal, e que havendo dinheiro em caixa nas 
prefeituras para financiamento de políticas públicas/programas sociais, não pressiona aos gestores municipais a arrecadar de forma eficiente os impostos do referido ente subnacional.

A variável receitapropria consiste na receita oriunda de diversas fontes extraídas dentro do município por meio da tributação na arrecadação de impostos, taxas e contribuições de melhoria, id est, a receita gerada dentro do território municipal dado o emprego das atividades econômicas, que se dá por meio da arrecadação de impostos constitucionalmente sob incumbência das prefeituras, tais como o Imposto Predial Territorial Urbano (IPTU), o Imposto Sobre Serviços (ISS) e o Imposto de Transmissão de Bens Intervivos (ITBI), além de taxas e contribuições de melhorias, de acordo com a legislação em vigor.

As variáveis independentes $\beta_{1} \ln$ (pibagrigola), $\beta_{2} \ln$ (pib industrial) e $\beta_{3} \ln$ (pib serviço), representam o tamanho da influência dos setores da economia atuantes no município sob as receitas locais por meio da arrecadação tributária. Tendo em vista que em dado município se há uma economia mais desenvolvida que em outros, este tende a possuir melhor arrecadação tributária.

Já a variável independente $\beta_{4} \ln$ (população) diz respeito a possibilidade de que em cidades mais populosas, se há uma tendência a possuir uma arrecadação tributária mais elevada que em cidades populosamente menores.

$\mathrm{E}$ por último a variável independente $\beta_{5} \ln (\operatorname{cota}$ do $\mathrm{fpm}$ ), onde convém mencionar que de acordo com a literatura econômica existe um forte poder de influência das transferências intergovernamentais sobre a tributação municipal, tendo em vista que este ente subnacional recebe recursos dos demais entes federativos, a de maior destaque é o Fundo de Participação dos Municípios (FPM) que é composto por $22,5 \%$ do Imposto de Renda (IR) e do Imposto sobre Produtos Industrializados (IPI).

Estas transferências do FPM estão previstas legalmente por meio dos caputs do Art.159, inciso I, alínea "b", da Constituição Federal de 1988. E segundo aponta a literatura econômica, após a década de 1980 e aumento das alíquotas destas transferências, os municípios passaram por razões políticas a não estimular sua base tributária própria, causando com isto uma certa dependência e gerando possíveis ineficiências na arrecadação tributária, conforme visto na seção anterior. 
O que se pretende com o estudo desta variável independente é avaliar se a disponibilidade de receitas oriundas das transferências do FPM postas aos municípios intervém de forma a gerar ganhos ou perdas de eficiência na arrecadação dos municípios potiguares no período de 2002 a 2016.

\section{RESULTADOS}

Após extraídos os dados, e seguindo a estratégia metodológica conseguiu-se auferir os resultados que possibilitaram a análise em conformidade com os objetivos elencados em seções anteriores.

\subsection{ANÁLISE DESCRITIVA}

A partir dos dados contábeis extraídos da plataforma Finanças do Brasil (FINBRA), e comparando as variações anuais dos dados, obteve-se a seguinte taxa de crescimento da receita tributária e o fundo de participação dos municípios presente no gráfico 1 abaixo:

Gráfico 1 - Taxas de Crescimento da Receita Tributária Própria e do Fundo de Participação dos Municípios.

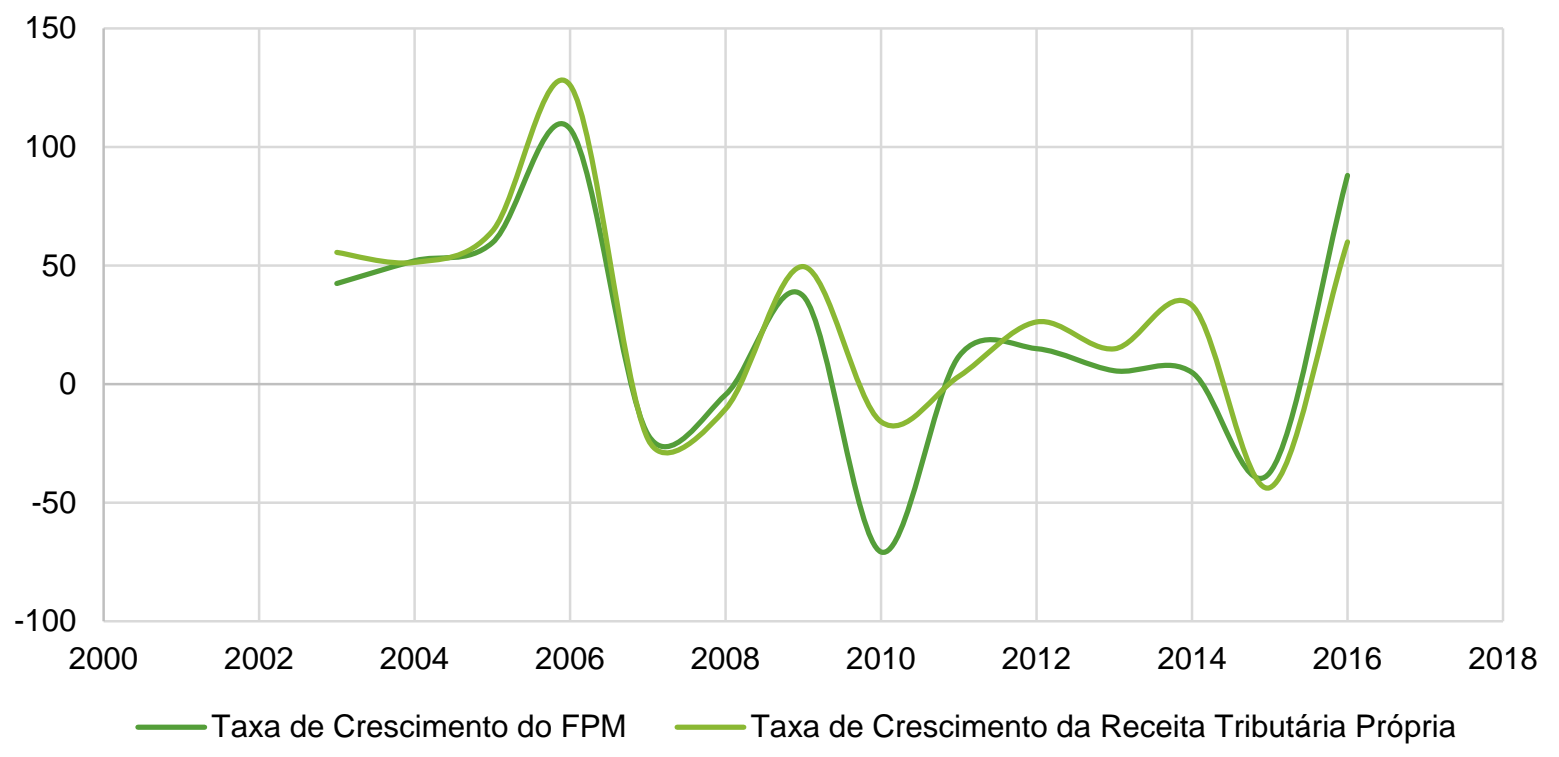

Fonte: Elaboração própria com base nos dados do FINBRA/STN.

No gráfico acima pode-se observar uma oscilação significativa nas fontes de receitas acima elencadas, porém é possível observar que a taxa de crescimento da 
receita tributária própria destes municípios se manteve durante maior parte do período igual ou superior ao volume de transferências do Fundo de Participação dos Municípios (FPM). No período em análise, as receitas variaram quase que proporcionalmente, onde ambas atingiram o ponto mais alto em 2006, com variações acima de $100 \%$. O ponto mais baixo de variação das transferências do FPM se deu em 2010 onde caiu 70\% em relação ao ano anterior. Quanto a maior queda da arrecadação própria se deu no ano de 2015 , onde caiu $43 \%$ em relação ao ano anterior, lembrando que nesse período o houve uma grave crise econômica.

Com base nos dados obtidos pelo Instituto Brasileiro de Geografia e Estatística (IBGE), elaborou-se a taxa de crescimento do PIB setorial dos municípios potiguares, os quais são apresentados no gráfico 2:

Gráfico 2 - Taxa de Crescimento do PIB setorial potiguar.

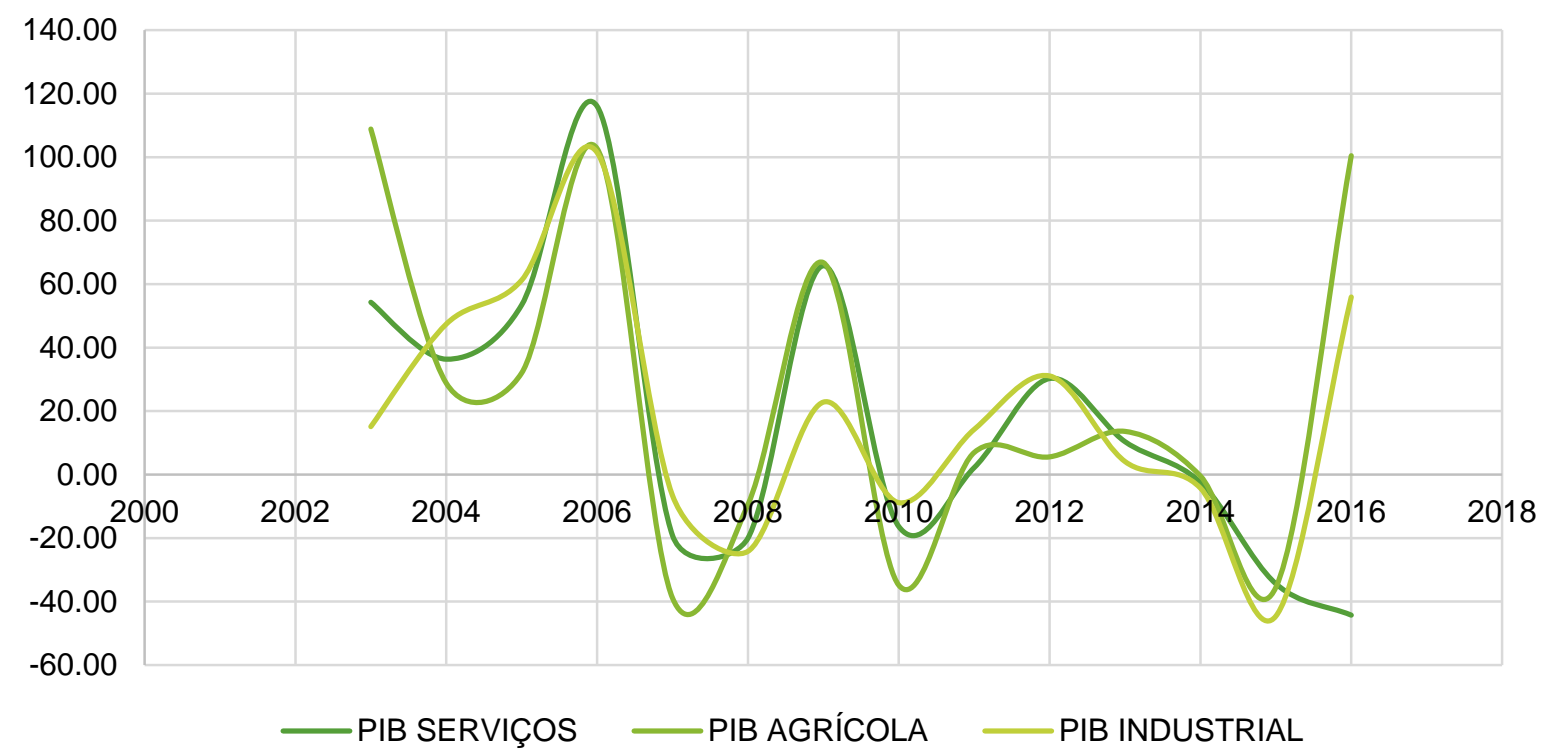

Fonte: Elaboração própria com base nos dados do IBGE.

Conforme as receitas, percebe-se que o PIB setorial dos municípios oscilou bastante durante o período estudado, obtendo maiores níveis de crescimento no ano de 2006, onde atingiram níveis acima de 100\%, e menores níveis nos anos de 2007, 2010 e 2015, sendo estes dois últimos ocasionados, respectivamente, pela crise mundial instaurada em 2008, que refletiu no Brasil nos anos subsequentes, e a crise brasileira de 2014 que se estendeu aos períodos seguintes. 
É possível observar que o PIB tanto crescia quanto decrescia proporcionalmente nos três setores estudados, sendo que o setor de serviços se manteve em sua maior parte do tempo oscilando acima dos demais, com exceção nos anos de 2014 a 2016, onde devido ao início da crise econômica recente, o setor de serviços seguiu em queda até o fim do recorte temporal, enquanto os setores agrícola e industrial mantiveram-se em elevação.

É perceptível a semelhança do comportamento entre os dois gráficos, sendo que em períodos onde os PIB setoriais cresceram, o mesmo ocorreu com as receitas municipais, seja por parte da arrecadação tributária municipal ou pela cota-parte do FPM. O mesmo ocorreu nos períodos de decrescimento do PIB face as receitas municipais. Assim, em períodos de economia aquecida a arrecadação se eleva devido a melhor possibilidade para incidir impostos dado o desempenho da atividade econômica atuante no município. Do contrário, em períodos de desaquecimento econômico se há uma tendência a redução das receitas tributárias, tendo em vista que não há uma melhor facilidade na cobrança dos impostos, possibilitando com isto perdas de eficiência tributária.

\subsection{ANÁLISE DA EFICIÊNCIA}

Após a estimação da Fronteira Estocástica de Produção de Impostos, que consiste num modelo de eficiência produtiva onde se há uma correlação entre a alocação entre insumos (inputs) e resultados (outputs) que possibilita ganhos de eficiência produtiva a firma. Os dados foram obtidos pela plataforma Finanças do Brasil (FINBRA) que fornece dados informados pelos municípios a Secretaria do Tesouro Nacional (STN), além de dados do Instituto Brasileiro de Geografia e Estatística (IBGE).

Ao aplicar a fronteira, obteve-se os seguintes resultados dos coeficientes que são o efeito das variáveis estudadas sobre a arrecadação tributária dos municípios potiguares, conforme a tabela 1 . 
Tabela 1 - Estimativas da Fronteira Estocástica de Produção de Impostos

\begin{tabular}{lccc}
\hline & Estimativa & Estatística Z & P-Value \\
\hline (Intercepto) & -6.3261 & -12.4036 & $<2.2 \mathrm{e} 16^{\star \star *}$ \\
$\log$ (Cota do FPM) & -0.80141 & 19.4237 & $<2.2 \mathrm{e}-16^{* * *}$ \\
$\log$ (PIB Agrícola) & 0.048073 & 1.7065 & 0.0879152 \\
$\log$ (PIB Industrial) & 0.10439 & 4.1707 & $3.037 \mathrm{e}-05^{\star * *}$ \\
$\log$ (PIB Serviços) & 0.13185 & 3.6460 & $0.0002664^{* * *}$ \\
$\log ($ População) & 0.42645 & 12.7592 & $<2.2 \mathrm{e}-16^{* * *}$ \\
SigmaSq & 0.74487 & 28.0927 & $<2.2 \mathrm{e}-16^{* * *}$ \\
Gamma & $1.0229 \mathrm{e}-05$ & 0.0049 & 0.9961194
\end{tabular}

Log likelihood value:

$-2041.019$

Fonte: Elaboração própria com base nos resultados da Fronteira Estocástica.

Evidenciou-se que estatisticamente os coeficientes obtiveram um nível de significância de $1 \%$, possibilitando com isto que as variáveis elencadas de fato interferem na arrecadação dos municípios potiguares no recorte de tempo em análise. A única variável não significante foi a variável independente PIB Agrícola, o que se pode presumir é que esta variável não possui influência sobre a eficiência da arrecadação tributária dos municípios do estado.

As variáveis independentes Cota FPM, PIB Industrial, PIB Serviços e População foram estatisticamente significativas, id est, são variáveis que influenciam sejam positivamente ou negativamente na variável dependente arrecadação tributária própria destes municípios. Neste caso, os PIB setoriais, com exceção do PIB Agrícola, são os determinantes da eficiência na arrecadação tributária própria municipal, influenciando-a positivamente.

No período de 2002 a 2016 nos municípios potiguares a variável independente Cota FPM auferiu o coeficiente de $-0,80$, ou seja, o FPM reduz a eficiência na arrecadação própria dos municípios potiguares. Isto significa dizer que a cota-parte destinada aos municípios do Fundo de Participação dos Municípios (FPM) causou um efeito "preguiça fiscal" no período em análise nos municípios norte-rio-grandenses. A medida contanto que foram-se disponibilizando às prefeituras fatias do FPM, estas acabaram por não estimular a arrecadação tributária local. E por se tratar de um alto volume de receita, esta ocasionou uma dependência das transferências do FPM para financiamento das políticas públicas municipais. O 
mesmo efeito foi observado nos municípios pernambucanos através das constatações de Siqueira, Lima e Paes (2016), assim como nos municípios gaúchos de acordo com Ribeiro (1999), conforme visto na seção 2 deste trabalho.

A partir da aplicação do modelo empírico, os resultados dos coeficientes da fronteira estocástica nos municípios do Rio Grande do Norte notaram-se que em se tratando dos setores da economia, o setor de serviços foi o que mais contribuiu para a eficiência tributária dos municípios, este apresentou o coeficiente de 0,13, enquanto o setor industrial apresentou o coeficiente de 0,10 , seguido do setor agrícola com 0,04. Este já era um resultado esperado tendo em vista a estrutura tributária dos entes subnacionais herdada da constituição federal de 1988, no qual definiu como competência das prefeituras municipais a arrecadação do Imposto Sobre Serviços.

A razão para isto se dá por que a arrecadação própria dos municípios se baseia em sua maior parte no recolhimento dos impostos constitucionais, que são o IPTU, o IBTI, e o ISS, sendo que este último é extraído a partir da atividade econômica atuante no município, o que possibilita maiores ganhos de receita (MORAES, 2006; CARVALHO JR, 2006). Em estudos de mesma natureza, como o de Siqueira, Lima e Paes (2016) que aplicou a fronteira estocástica aos municípios do estado do Pernambuco, observou-se que este setor também possuía maior influência sobre os demais sobre a eficiência na arrecadação tributária.

A variável independente população foi a que mais influenciou positivamente a eficiência nas receitas tributárias municipais atingindo o coeficiente de 0,42 , ou seja, a arrecadação dos municípios pode variar conforme o número populacional de habitantes deste. $\mathrm{E}$, se tratando de cidades pequenas onde o número populacional é inferior aos grandes centros urbanos, esta tenderá a gerar menos receita que as de maior número de habitantes. A justificativa para isto se dá face ao pressuposto em que quanto mais populosa for a cidade, e esta deter um maior nível de PIB per capita, esta tende a possuir uma arrecadação igualmente proporcional, de acordo com os argumentos por Queiroz e Postali (2010).

No geral, ao longo de todo o período estudado, os maiores níveis de eficiência se deram no ano de 2014, onde o município de Acari atingiu um coeficiente de 0,91, seguido dos municípios de Itajá, Serra Negra do Norte e Serrinha dos Pintos ambos com o coeficiente de 0,90. Quanto aos que atingiram menores níveis de eficiência do recorte temporal foram os municípios de Macaíba, 
com o coeficiente de 0,76, seguido dos municípios de Currais Novos, Natal e CearáMirim com 0,77, ambos também se deram no exercício de 2014. A média geral no período de 2002 a 2016 o nível de eficiência na arrecadação tributária dos municípios potiguares foi de 0,84, ou seja, uma média 0,16 da capacidade tributária dos municípios não é explorada eficientemente por meio das prefeituras.

A partir dos resultados dos coeficientes de eficiência dos municípios estimados por meio da Fronteira Estocástica de Produção de Impostos, foi possível elaborar um mapa do estado do Rio Grande do Norte apresentando a distribuição espacial dos coeficientes médios de eficiência dos municípios, para o período em análise. Conforme pode-se observar na figura 1.

Figura 1 - Distribuição espacial dos coeficientes de eficiência.

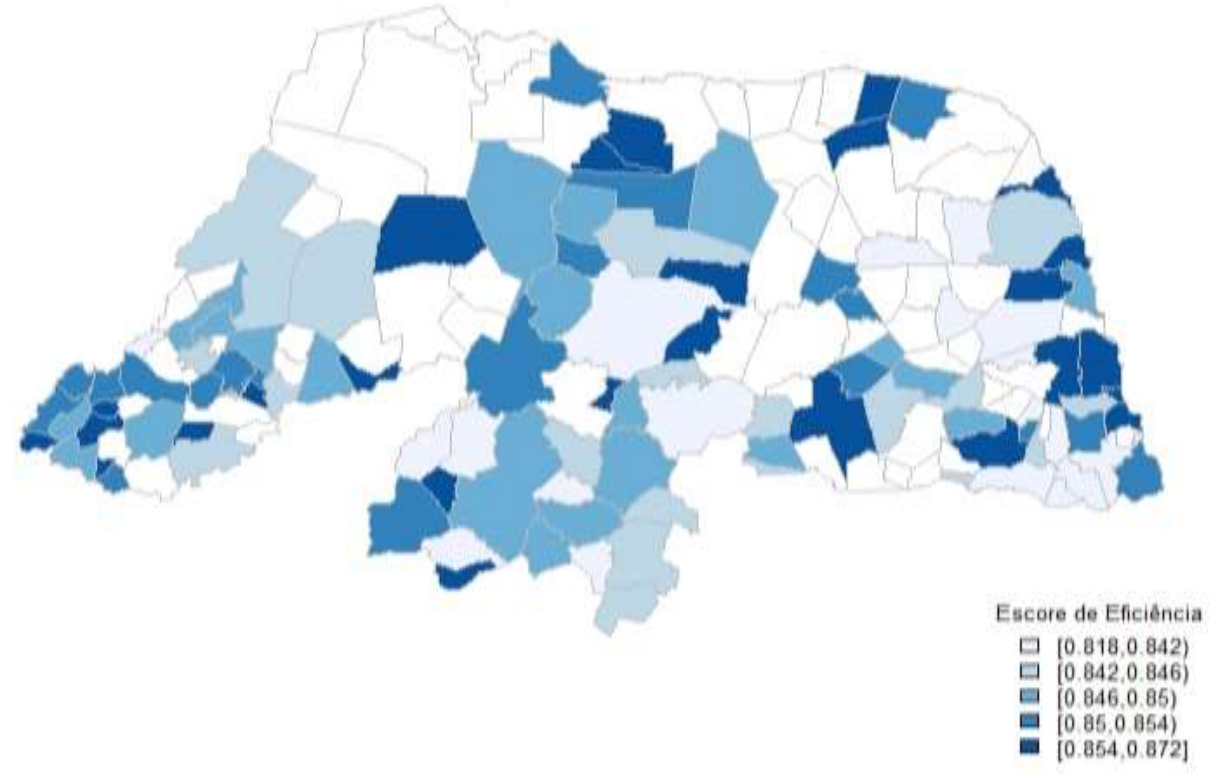

Fonte: Elaboração Própria.

Analisando o mapa, é possível observar que inexiste uma expressiva correlação espacial entre os municípios estudados, tendo em vista as significativas variações nos coeficientes de eficiência da maioria dos municípios, onde os níveis de eficiência variam nas diferentes regiões do estado. Ao contrário das constatações de Siqueira, Lima e Paes (2016), em relação aos municípios pernambucanos.

No entanto, percebe-se que em algumas regiões, devido as características socioeconômicas dos municípios possuírem semelhanças, existe uma tendência a refletir sobre a situação fiscal destes municípios. De modo, que em municípios que 
possuem as dinâmicas econômicas semelhantes aos municípios circunvizinhos, tendem a possuir níveis de eficiência semelhantes aos demais.

\section{CONSIDERAÇÕES FINAIS}

Este estudo teve o objetivo verificar os determinantes da eficiência na arrecadação tributária dos municípios potiguares no período de 2002 a 2016. Os dados empregados na pesquisa foram extraídos da plataforma Finanças do Brasil (FINBRA), que detém dados da Secretaria do Tesouro Nacional (STN) e da Caixa Econômica Federal (CEF), além de dados obtidos do Instituto Brasileiro de Geografia e Estatística (IBGE).

Em análise da evolução das receitas tributárias próprias dos municípios, percebe-se que houve muitas oscilações no período em análise. Em comparação com o Fundo de Participação dos Municípios (FPM), a arrecadação própria mantevese na maior parte do tempo com taxas de crescimento igual ou superior às taxas de crescimento do FPM, variando quase que proporcionalmente.

Porém se observou que nos períodos de crise econômica como nos anos de 2009 e 2010, devido à crise mundial de 2008, e posteriormente em 2015, a arrecadação própria atingiu os menores níveis de crescimento, acompanhando assim, na maior parte do período, a trajetória dos níveis de crescimento do PIB setorial de Serviços, Indústria e Agrícola.

Após a aplicação da fronteira estocástica de produção de impostos, observouse que em toda a trajetória do recorte temporal os coeficientes de eficiência dos municípios obtiveram níveis de eficiência que variaram entre 0,76 a 0,91. Sendo o menor nível de eficiência no município de Macaíba, e o maior nível de eficiência no município de Acari. Ambos os extremos foram registrados no ano de 2014. A média geral da eficiência dos municípios no período em análise foi de 0,84 , o que significa dizer que as prefeituras não exploram uma média de 0,16 da capacidade de arrecadação dos municípios.

Observou-se também que dentre as variáveis que influenciaram na eficiência da arrecadação própria dos municípios, a variável população foi a que mais influenciou positivamente sobre a variável dependente. Seguida das variáveis, PIB de serviços que obteve nível de influência de 0,13 , PIB industrial com o coeficiente 
de 0,10 e PIB agrícola que obteve coeficiente de 0,04, não obtendo nível de significância para a pesquisa.

A cota-parte do Fundo de Participação dos Municípios (FPM), obteve um coeficiente de -0,80, afetando de forma negativa a arrecadação própria dos municípios potiguares no período em análise, impactando diretamente em sua eficiência. Este já era um resultado esperado, tendo em vista que a literatura econômica aponta que o volume de transferências do FPM acaba por desestimular a arrecadação própria dos municípios, de forma a causar um efeito "preguiça fiscal" sobre as receitas. Isto se justifica por fatores políticos, que possibilitam aos gestores municipais a não explorar com mais intensidade a capacidade tributária destes municípios para não gerar "desgaste político" junto à população.

Foi possível observar ainda, que em relação a eficiência tributária dos municípios não existe uma correlação espacial, porém em algumas regiões do estado, devido as características econômicas similares nos municípios, se há uma tendência com que municípios circunvizinhos possuam níveis de eficiência tributária semelhantes.

Após a análise dos resultados, podemos presumir que este estudo atendeu aos objetivos e questionamentos propostos na introdução deste trabalho, assim como preencheu uma lacuna quanto a literatura econômica aplicada aos municípios do Estado do Rio Grande do Norte.

\section{REFERÊNCIAS}

AFONSO, José Roberto Rodrigues; VARSANO, Ricardo; RAMUNDO, Julio César Maciel; ARAUJO, Erika Amorim; PESSOA, Elisa de Paula; SILVA, Napoleão Luiz Costa da. TRIBUTAÇÃO NO BRASIL: CARACTERÍSTICAS MARCANTES E DIRETRIZES PARA A REFORMA. Revista do BNDES, Rio de Janeiro, v. 5, n. 9, p. 25-50, jun. 1998. Disponível em:

https://web.bndes.gov.br/bib/jspui/bitstream/1408/11454/1/RB\%2009\%20Tributa\%C3 \%A7\%C3\%A30\%20no\%20Brasil\%20\%20caracter\%C3\%ADsticas\%20marcantes\%2 0e\%20diretrizes\%20para\%20a\%20reforma_P_BD.pdf. Acesso em: 12 out. 2018.

AFFONSO, Rui. Os Municípios e os Desafios da Federação no Brasil. São Paulo em Perspectiva, 1996. Disponível em: <http://www.seade.gov.br/wpcontent/uploads/2014/07/v10n3.pdf>. Acesso em: 18 set. 2017. 
AIGNER, Dennis; LOVELL, C.A. Knox; SCHMIDT, Peter. FORMULATION AND ESTIMATION OF STOCHASTIC FRONTIER PRODUCTION FUNCTION MODELS. Journal of Econometrics, v. 6, p. 21-37, 1977. Disponível em: <https://pdfs.semanticscholar.org/3d6c/a6a699e579463e0b01526d9842d41f26b314. pdf>. Acesso em: 20 nov. 2018.

BATTESE, George E. Frontier production functions and technical efficiency: a survey of empirical applications in agricultural economics. Agricultural economics, v. 7, n. 3-4, p. 185-208, 1992. Disponível em: $<$ https://ageconsearch.umn.edu/bitstream/172957/2/agec1992v007i003004a001.pdf>. Acesso em: 20 nov. 2018.

BOUERI, Rogério; CARVALHO, Alexandre Xavier Ywata; SILVA, Fernanda Rocha Gomes. EFICIÊNCIA TRIBUTÁRIA DOS ESTADOS BRASILEIROS MENSURADA COM UM MODELO DE FRONTEIRA ESTOCÁSTICA GEOGRAFICAMENTE PONDERADA. Instituto de Pesquisa Econômica Aplicada (IPEA), 2009. Disponível em: <http://www.ipea.gov.br/portal/images/stories/PDFs/TDs/td_1444.pdf>. Acesso em: 29 abr. 2019.

BRASIL, Constituição Federal de 1988. Promulgada em 5 de outubro de 1988. Disponível em: <http://www.planalto.gov.br/ccivil_03/constituicao/constituicao.htm>. Acesso em: 9 set. 2017.

CAMARGO, Francielle de O.; GUIMARÃES, Klicia M. S. O PRINCÍPIO DA EFICIÊNCIA NA GESTÃO PÚBLICA. Revista CEPPG - CESUC - Centro de Ensino Superior de Catalão, Ano XVI no 28, 1ํ Semestre/2013. Disponível em:

$<$ http://www.portalcatalao.com/painel_clientes/cesuc/painel/arquivos/upload/downloa ds/376b38ef01c9b0caae5d67f8c6bf4d03.pdf>. Acesso em: 03 out. 2018.

CARLOS, Amanda Pimenta; ALVES, Rodrigo de Barros. A economia política da carga tributária brasileira, 1947-2002. Anais do XXXVI Encontro Nacional de Economia. Anais... Salvador: Associação Nacional dos Centros de Pós-Graduação em Economia (Anpec), 2008. Disponível em:

<http://www.anpec.org.br/encontro2008/artigos/200807211130040-.pdf>. Acesso em: 03 out. 2018.

CARVALHO JR, Pedro Humberto Bruno de. IPTU NO BRASIL: PROGRESSIVIDADE, ARRECADAÇÃO E ASPECTOS EXTRA-FISCAIS. Instituto de Pesquisa Econômica Aplicada (IPEA), 2006. Disponível em: $<$ http://repositorio.ipea.gov.br/bitstream/11058/2185/1/TD_1251.pdf>. Acesso em: 23 abr. 2019.

GIAMBIAGI, Fabio; ALÉM, Ana Cláudia. Finanças Públicas. 2 ed. Rio de Janeiro: Campus, 2000. 475 p.

GOMES, Gustavo Maia; MAC DOWELL, Maria Cristina. Descentralização Política, Federalismo Fiscal e Criação de Municípios: O que É Mau para o Econômico nem sempre é Bom para o Social. Instituto de Pesquisa Econômica Aplicada (IPEA), 2000. Disponível em: 
<http://repositorio.ipea.gov.br/bitstream/11058/2339/1/TD_706.pdf>. Acesso em: 8 out. 2017.

MASSARDI, Wellington de Oliveira; ABRANTES, Luiz Antônio. DEPENDÊNCIA DOS MUNICÍPIOS DE MINAS GERAIS EM RELAÇÃO AO FPM. Gestão, Finanças e Contabilidade, v. 6, n. 1, 2016. Disponível em: <http://www.atena.org.br/revista/ojs2.2.3-06/index.php/RGFC/article/viewFile/173-187/2279>. Acesso em: 29 abr. 2019.

MENDES, Marcos. Federalismo Fiscal. In: AVARTE, Paulo; BIDERMAN, Ciro. Economia do Setor Público no Brasil. Rio de Janeiro: Elsevier, 2004. cap. 22, p.421-461.

MENDES, Marcos; MIRANDA, Rogério Boueri; COSIO, Fernando Blanco.

TRANSFERÊNCIAS INTERGOVERNAMENTAIS NO BRASIL: diagnóstico e proposta de reforma. Consultoria Legislativa do Senado Federal/Coordenação de Estudos, 2008. Disponível em:

<https://www2.senado.leg.br/bdst/bitstream/handle/id/94747/Textos\%20para\%20disc uss\%C3\%A3o\%2040.pdf?sequence=7>. Acesso em: 20 out. 2017.

MODESTO, Paulo. Notas para um debate sobre o princípio da eficiência. Revista de Direito Administrativo \& Constitucional, 2001. Disponível em:

<http://www.revistaaec.com/index.php/revistaaec/article/view/767/574>. Acesso em: 29 abr. 2019.

MORAES, David Polessi de. ARRECADAÇÃO TRIBUTÁRIA MUNICIPAL: Esforço Fiscal, transferências e Lei de Responsabilidade Fiscal. Fundação Getúlio Vargas (FGV), 2006. Disponível em:

<http://bibliotecadigital.fgv.br/dspace/bitstream/handle/10438/2421/155046.pdf?sequ ence=3\&isAllowed=y >. Acesso em: 13 mar. 2019.

QUEIROZ, Carlos Roberto Alves; POSTALI, Fernando Antonio Slaibe. Rendas do Petróleo e Eficiência Tributária dos Municípios Brasileiros. Revista Economia \& Tecnologia, v. 6, n. 3, 2010. Disponível em:

<https://revistas.ufpr.br/ret/article/view/26963/17983>. Acesso em: 09 mai. 2019.

REIS, Eustáquio J.; BLANCO, Fernando A. CAPACIDADE TRIBUTÁRIA DOS

ESTADOS BRASILEIROS, 1970/90. Instituto de Pesquisa Econômica Aplicada (IPEA), 1996. Disponível em:

<http://repositorio.ipea.gov.br/bitstream/11058/1751/1/td_0404.pdf>. Acesso em: 18 out. 2018.

RIBEIRO, Eduardo Pontual. Capacidade, eficácia e eficiência tributária no Rio Grande do Sul: municípios. Universidade Federal do Rio Grande do Sul, Programa de Pós-Graduação em Economia, 1999. Disponível em:

https://www.researchgate.net/profile/Eduardo_Ribeiro8/publication/267377084_Capa cidade_Eficacia_e_Eficiencia_Tributaria_no_Rio_Grande_do_Sul_Municipios/links/5 5ae3fa308aed614b099ae87.pdf. Acesso em: 29 abr. 2019. 
SAMPAIO, Maria da Conceição. Tributação do consumo no Brasil: aspectos teóricos e aplicados. In: AVARTE, Paulo; BIDERMAN, Ciro. Economia do Setor Público no Brasil. Rio de Janeiro: Elsevier, 2004. cap. 11, p.188-205.

SIQUEIRA, Kleyton José da Silva Pereira de; LIMA, Ricardo Carvalho de Andrade; PAES, Nelson Leitão. Eficiência na administração tributária dos municípios: o caso da arrecadação em Pernambuco. Revista Brasileira de Economia de Empresas, v. 16, n.2, 2016. Disponível em:

https://portalrevistas.ucb.br/index.php/rbee/article/view/6183/4701. Acesso em: 29 abr. 2019.

SIQUEIRA, Rozane Bezerra de; NOGUEIRA, José Ricardo; BARBOSA, Ana Luiza Neves de Holanda. Teoria da tributação ótima. In: AVARTE, Paulo; BIDERMAN, Ciro. Economia do Setor Público no Brasil. Rio de Janeiro: Elsevier, 2004. cap. 10, p.173-187. 